\title{
The Potential and Limitations of Twitter Activism: Mapping the 2011 Libyan Uprising
}

\author{
Simon Lindgren
}

\author{
Umeå University, Umeå, Sweden, simon.lindgren@soc.umu.se, www.simonlindgren.com
}

\begin{abstract}
This article aims to shed more light on the potentials and limitations of social media as a tool for activists. It does this by focusing on the use of one particular social media platform - Twitter - during one specific period of a certain uprising: the first 24 hours of protests in Libya during the Arab Spring in 2011. Even though this study is thus limited, it represents an important step in the direction of analyzing what actually happens when social media is put to use in relation to concrete events. The identified social network patterns, as well as the content of the posts, resonate with what Enzensberger (1970) calls "emancipatory use of media": The architecture is decentralized, network connections are distributed, and mobilization and self-organization is going on. It must be realized however, that seeds of such emancipatory use does not necessarily preclude "repressive use of media".
\end{abstract}

Keywords: Activism, Social Media, Networks, Discourse

Acknowledgement: This research was kindly funded by the Swedish Council for Working Life and Social Research (FAS).

Much attention is directed towards the role of networked digital media in political processes around the world. Particularly, much discourse relates to the alleged potential of new computerized tools and platforms as regards the possibilities of grassroots interest groups, social movements, NGOs and oppressed populations to voice their concerns, talk back to the powers that be, and to actually make a difference. A number of uprisings across the globe during the last couple of years have popularly been labeled Twitter Revolutions: the civil unrest following the 2009 elections in Moldova (Munteanu and Mungiu-Pippidi 2009), the Iranian election protests in 2009 and 2010 (Burns and Eltham 2009; Grossman 2009), the 2010-2011 Tunisian protests against the Ben Ali regime, and the 2011 Egyptian protests against President Mubarak (Jansen 2010). During the second part of 2011, the events during the so called Arab Spring have often been bundled together with the emergence of the Occupy Movement (Gessen 2012) in discussions of "why it's kicking off everywhere" (Mason 2012; Skinner 2011).

What unifies all of these cases is that (allegedly) democratized social media (Twitter, Facebook etc.) have been employed by the people to promote their causes, organize protests and to disrupt and circumvent the official flows of information stemming from traditional media or economic and governmental institutions. Throughout the last few years, processes like these are becoming increasingly highlighted also in somewhat less tumultuous political contexts. For example, Barack Obama's victory in the 2008 US presidential election has been widely attributed to the mobilization of a broad grassroots movement on the internet (Boehlert 2009; Harfoush 2009), and the role of the internet in democratic elections has been discussed by a number of scholars (Anstead and Chadwick 2008; Gibson, Römmele and Ward 2003; Hooghe and Teepe 2007; Tolbert and Mcneal 2003; Vergeer, Hermans and Sams 2011). 


\section{Assessing the Potentials and Limitations of Social Media as an Activist Tool}

Today, some researchers claim that networked publics (Varnelis, 2008), 'smart mobs' (Rheingold 2002), and other online groups may function as actual political forces (Chadwick and Howard 2008; Kahn and Kellner 2003). Poster $(2009,692)$ identifies a shift from elite production of culture to a digital meaning-production by the masses. According to that view, the relationship between center and periphery has been dislocated, or dissolved, to the point where one can no longer speak of any one node where the power over symbolic production is concentrated. Ideas like these give rise to the vision of a new society where consumers and producers of content and ideas melt into one and where power structures are overthrown.

In the wake of these developments, a certain friction has developed in public debate as well as in new media research. Some commentators focus mainly on the optimistic analysis of the potential for new media audiences to come together, subvert power structures, and take control over the flows of communication in society (Jenkins 2006; Mason 2008; Shirky 2009), while others are more pessimistic and underline the risk of over-emphasizing the democratizing potentials of social media and forgetting that power structures prevail and may even be strengthened by these same media (Fuchs 2011; Keen 2007; Morozov 2011).

When it comes to the democratizing potential of new media, already Adorno and Horkheimer (1947) were skeptical about the celebration of the media that were new in the mid-20th century (radio, television and film). According to them, arguments about the liberating potential of the new media had just as much to do with generating economic profit for private media corporations, as with actually making the audience play a larger part in political processes. According to Adorno and Horkheimer, "the cultural industry" not only controlled technology and content, but they also contributed largely to the shaping of opinions and consent in relation to the prevailing social institutions. Similarly today, political mobilization, participation and activism through social media may firstly be obstructed by the fact that big media companies and governments are dominating public discourse to the extent where it is impossible for the tail of individual users, however long it may be (Anderson 2006), to form any substantial and sufficiently homogenous counter-force (Downey and Fenton 2003; Fraser 1990). Secondly, activism through social media has been said to promote a watered down and non-engaged mode of "slacktivism" (Christensen 2011; Morozov 2009) or "clicktivism" (White 2010) where we are mistaking low-threshold user behaviors similar to that of marketing campaigns for actual commitment and sacrifice.

This article represents an attempt to shed more light on the potentials and limitations of social media as a tool for activists. It does this by focusing on the use of one particular social media platform - Twitter - during one specific period of a certain uprising: the first 24 hours of protests in Libya during the Arab Spring in 2011. Even though this study is thus limited, it represents an important step in the direction of analyzing what actually happens when social media is put to use in relation to concrete events. Ultimately, the issue of what these tools might achieve or not is not a philosophical or theoretical question, but an empirical one that can be explored through systematic analysis of actual circumstances and patterns. The study is based on connected concept analysis (Lindgren 2012) and social network analysis (Wasserman and Faust 1994) of a dataset representing communication employing the \#feb17 hashtag.

\section{The Arab Spring and New Media}

While this article looks at how the social medium of Twitter was used during the early stage of the Libyan uprising, it is important to keep in mind that this event was not by any means a purely social media phenomenon as such. Nor was the Arab Spring the result of an unambiguous and coherent movement. Anderson $(2011,2)$ points this out: "The important story about the 2011 Arab revolts in Tunisia, Egypt, and Libya is not how the globalization of the norms of civic engagement shaped the protesters' aspirations. Nor is it about how activists used technology to share ideas and tactics. Instead, the critical issue is how and why these ambitions and techniques resonated in their various local contexts." 
In fact, the demographics as well as the patterns of the protests differed largely (Joffé 2011). The Tunisian protests resonated with the cause of the country's long repressed labor movement, and started in rural areas gradually gravitating towards the capital. In contrast to this, the Egyptian uprisings were organized in urban settings by young cosmopolitans. In Libya, on the other hand, armed rebels in the eastern provinces started the uprising, stirring up decade-old conflicts between tribes and regions. Protesters in Egypt and Tunisia were able to quickly form spontaneous and effective social movements, while similar attempts to form movements in Libya collapsed into civil war (ibid., 511). So while all of these uprisings were consequences of fragile socio-political and economic regimes - and while they all were "the consequence of social movements emerging from the semi-autonomous organisations created through the process of partial liberalisation in liberalised autocracies" (ibid., 517) - their contexts were still largely different.

So even if social media was a component of the events in these countries - as well as consequently Syria, Yemen, and Bahrain - it was by no means the strong catalyst, or driving force, that it has sometimes been portrayed to be. The countries were "ready for revolutionary movements due to an assortment of politico-economic conditions" (Khondker 2011, 678). According to Joffé (2011) neither mobile phones nor the internet as such were of any key importance for the success of the demonstrations. In Tunisia and Egypt both of these technologies were closed down during substantial periods of the - still growing demonstrations. In fact, older technologies (i.e. satellite television which is both universally accessible and much harder to close down) might have been of much bigger importance for how the events played out.

Still, some researchers claim that social media actually did play a deciding role for the North African revolutions of 2011. Khondker $(2011,676)$, for example, writes of the emergence of a "cyber-civil society" and claims that social media was of key importance for the events. Facebook was used to spread important news that were crucial for the early stages of the Tunisian uprising. Furthermore, social media is said to have played a key role for how the Tunisian revolution spilled over into Egypt. Thereafter, "(t)he Egyptian revolution was well organized, coordinated, and civil, and at every step the new media played its part" (ibid., 677). So even if Khondker states that the precence of revolutionary conditions was the most important cause for what happened, social media is still said to have been a very important catalyst. Some have even called the events 'Facebook Revolutions' or - as mentioned in the introduction to this article - 'Twitter Revolutions' (Munteanu and MungiuPippidi 2009; Smith 2011). But such over-simplifying labels merely point out that we need more empirical research that contributes to capturing "the broader, overlapping and interpenetrating ways in which media systems and communication networks have complexly conditioned and facilitated these remarkable historical events" (Cottle 2011, 647).

\section{Clusters of Activists and News Corporations}

In the following empirical case study of Twitter activity during the first 24 hours of the Libyan uprising on 17 February 2011, I firstly look at the social network relations among the tweeters. Secondly, I will look at the uprising through its written discourse in the form of tweets (posts to Twitter). In concluding, these two levels are discussed together. The structure of any social field can be conceived of in terms of relations of symbolic power. This is because "the social world is a system of symbolic exchanges", and "social action is an act of communication" (Bourdieu 1977, 646). Language is social, and social interaction revolves per definition around various forms of language use.

Applying Bourdieu's field logic to the study of tweets, the key theoretical starting point for this paper is that "network architecture is politics" (Galloway 2004, 245). Relations of power exist by definition in any network, and the interconnections may be structured in "arbolic", tree-like and hierarchic, or "rhizomatic", anarchic and decentralized, structures (Deleuze and Guattari 1987). While so called alternative media have often been approached as being rhizomatic because of their underground character, elusiveness, interconnectedness and transcending character (Bailey, Cammaerts, and Carpentier 2008, 27), one must not assume 
that this is the fact with all social media. Rather, it can be argued that contemporary social media is largely run by corporations that exploit audiences as consumers and whose main goal is to generate surplus value (Fuchs 2011, 255-292).

Since 2007, Twitter users frequently employ so called hashtags - keywords marked with the \# symbol - to indicate discussion 'channels' within the largely unstructured flow of posts through the service. While often used in playful ways, hashtags have also proven to be efficient for constituting "ad-hoc publics" to mobilize people in relation to significant events (Bruns and Burgess 2011). The dataset analyzed in this study consists of all Twitter replies (directed public communication between accounts) using the \#feb17 hashtag during this particular day. Protests actually began on 15 February as a larger demonstration took place on the evening of that day outside of the police headquarters in Benghazi, following the arrest of human-rights activist Fathi Terbil. But a larger call for a "Day of Revolt" on 17 February, for all groups opposed to Gaddafi both within Libya and in exile, was made on the internet already at the beginning of the month. February 17th also ended up being the first day of a month of daily protests and violent clashes until the international military intervention began on 19 March 2011.

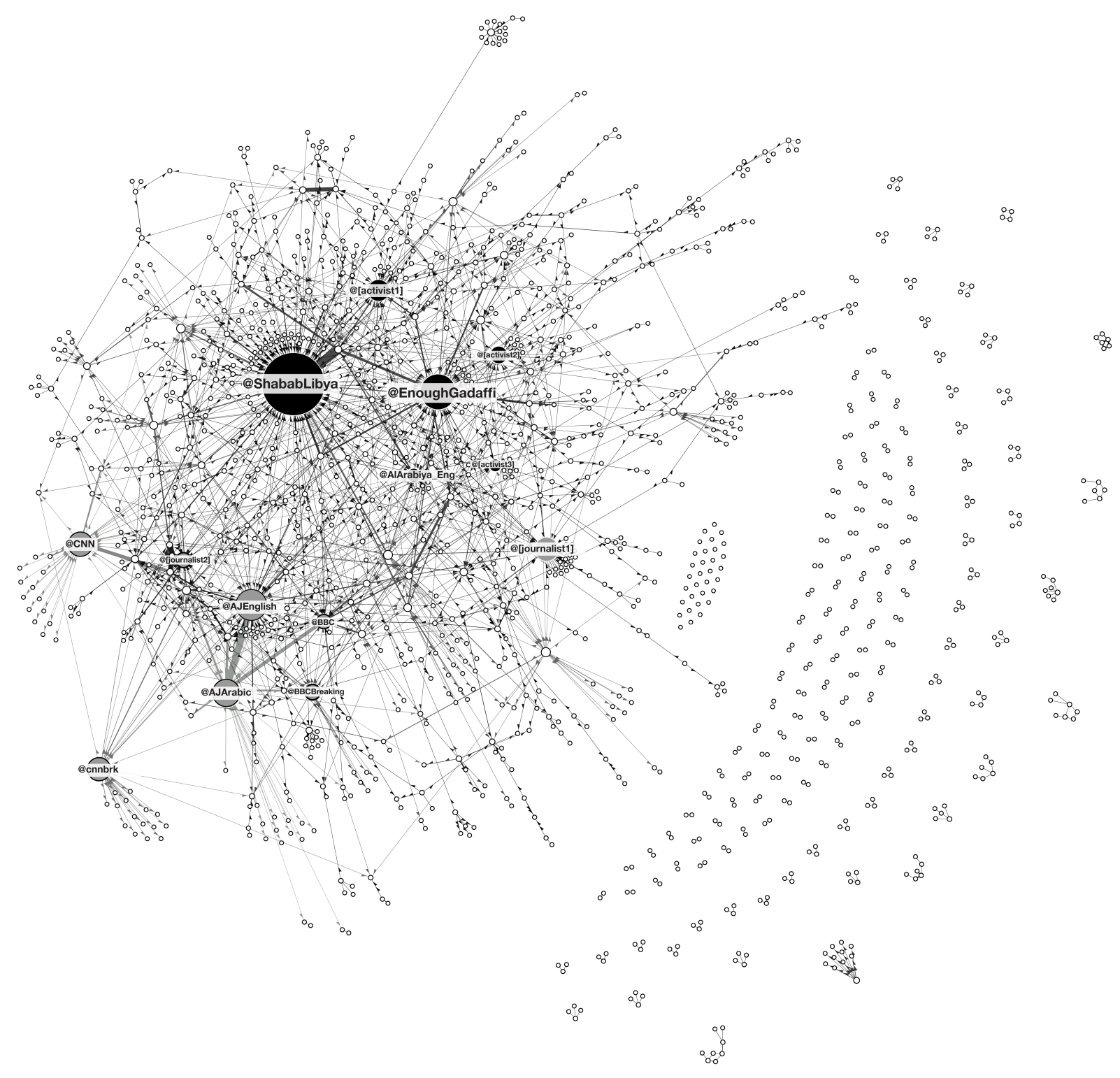

Figure 1: Social network graph of replies and mentions under the \#feb17 hashtag 
As tweets without an addressee, as well as pure retweets, were filtered away, the dataset ended up including 1,897 tweets. In order to perform a social network analysis (De Nooy, Mrvar, and Batagelj 2011; Wasserman and Faust 1994) of these data, Textometrica (Lindgren and Palm 2011) was used to identify connections between users. Gephi (Bastian, Heymann, and Jacomy 2009) was used to produce the network graph shown in Figure 1. This graph shows the entire network of directed tweets using the \#feb17 hashtag. The node sizes reflect how often a user is mentioned or replied to by any other user. As marked by different shades of grey in the graph, two key clusters could be identified. The first one of these is marked in black and includes the actors listed in Table 1.

\begin{tabular}{|l|l|l|l|}
\hline Account & Degree & Type & Country/Language \\
\hline$@$ ShababLibya & 130 & Activist organization & Libya/English \\
\hline @EnoughGaddafi & 72 & Activist organization & USA/English \\
\hline${\text { [activist1] }{ }^{\star}}^{\star}$ & 37 & Individual activist, citizen journalist & Libya/English \\
\hline [activist2] $^{\star}$ & 31 & Individual activist & USA/English \\
\hline @ [activist3] & 20 & Individual activist & USA/English \\
\hline @ AIArabiya_Eng & 11 & TV news channel & UAE/English \\
\hline
\end{tabular}

* Anonymized account

Table 1: Overview of nodes in the activist cluster

The network metric of "degree", indicated in the table, is a measure of centrality that reflects the number of ties that a node has. In other terms, the degree reflects the risk of a node being part of whatever flows through the network. In this particular case, the degree can be interpreted as the level of relative involvement in the discourse taking place in the ad hoc public forming under the \#feb17 hashtag. Generally, this cluster can be defined as an activist cluster as it comprises two activist organizations and three individual activists. At its periphery, we also find the twitter account of pan-arabist television news network Al Arabiya. The two organizations are Shabab Libya and Enough Gaddafi. Shabab Libya, or The Libyan Youth Movement, describes itself like this: "The Libyan Youth Movement was set up during the Jan 25 Egyptian Revolution, it's goal, to unite the Libyan Youth both inside and out of Libya in preparation for the February 17 uprising. Anticipating the media and communication blackout in Libya we quickly set up a database of contacts across the country so as to pass information from the ground in real time. We are now establishing a link with the Libyan Transitional Council in order to support the values we believe in as well as ensuring the voice of Libya's youth is heard. We do not belong to a political party, nor to any factions. We do not receive any financial backing. The Libyan Youth Movement is currently set up in a few countries across the world, if you would like to get involved please get in contact with us" (www.shabablibya.com/about).

In other words, this is an organization working both in and outside of Libya, with a specific focus on the day uprising planned for February 17. In anticipation of a media blackout, the organization works with the explicit aim of transmitting information "from the ground in real time". The other organization, Enough Gaddafi, is based in the US. "Enough is born from a single, broad sentiment: the recognition of the overwhelming need for change in Libya. Initiated by a group of second-generation Libyan exiles in the United States, Enough aims to engage all those who share this sentiment towards the betterment of Libya" (www.enoughgaddafi.com).

Aside from these two organizations, the cluster also includes three individual activists that have a prominent place in the discourse. The first activist, [activist1], claims to be a prodemocracy and pro-freedom fighter based in Tripoli working against tyranny and dictatorship. The Twitter account is connected to a Facebook page of the same name where it is stated that the person in question has the ambition of covering news from the Libyan revolution. Support for Shabab Libya is also expressed. The second activist, [activist2], does not provide 
any clear information in the Twitter profile, but telling from tweet content, followers, accounts followed and lists created, the individual seems to be highly active in a field very similar to that of [activist1]. Even if [activist2] does not provide any location data, network relations and language fluency suggest that this is a US based exile Libyan. The third one, [activist3], is a US based artist of Libyan descent who has an active presence on several social platforms on the internet, and who combines the promotion of performances and recordings with political messages relating to the uprising in Libya.

\begin{tabular}{|l|l|l|l|}
\hline Account & Degree & Type & Country/Language \\
\hline @AJEnglish & 61 & TV news channel & Quatar/English \\
\hline @ [journalist1] & 41 & TV news journalist/activist & Venezuela/Multi-Lingual \\
\hline @ AJArabic & 27 & TV news channel & Quatar/Arabic \\
\hline @CNN & 21 & TV news channel & USA/English \\
\hline @ cnnbrk & 21 & TV news channel & USA/English \\
\hline @ [journalist2] & 16 & TV news journalist & USA/English \\
\hline @BBC & 14 & TV news channel & UK/English \\
\hline @BBCBreaking & 13 & TV news channel & UK/English \\
\hline
\end{tabular}

${ }^{*}$ Anonymized account

Table 2: Overview of nodes in the news corporation cluster

The second key grouping, shown in Table 2, can be defined as a news corporation cluster as it consists of eight Twitter accounts, all related to major news corporations. Two of the accounts are connected to CNN, and thus US based, while two others are British and belong to the BBC. Yet another two accounts belong to Al Jazeera, which is located in Qatar, and two individual journalists own the final two accounts. These journalists work for two of the news corporations included in the cluster, and one of them is particularly active on Twitter in a way that moves beyond the role as journalist stretching into the realm of activism.

\section{Exploring the Continents of the Ad Hoc Public}

Summing up the analysis of these two clusters, communication under the \#feb17 hashtag appears to be centered around 14 Twitter accounts in and out of which a relatively substantial amount of tweets are flowing. Nearly all of this communication is done in English. Data on geolocation and language in the dataset are far from fully reliable (and also hopelessly incomplete), but a rough estimation is that the activists on Twitter are more than $75 \%$ North African, while the news media representatives are around $80 \%$ US and UK based.

The core accounts are in turn interconnected in two key clusters, and even though there are some overlaps, one can still discern a clear pattern in terms of an activist cluster on the one hand, and a news corporation cluster on the other. Looking at the degree metric, the activist cluster has a total degree of 301 and the news corporation cluster has 214 . While this indicates that the activist cluster is more influential than the news corporation cluster in terms of network flow, one must keep in mind that the sum total of network flow (degree) is 3,586 . This means that the two prominent clusters absorb and represent no more than 14 percent of all communication in the network. What is furthermore striking is that the nodes in the two key clusters are the Twitter accounts of traditional media companies and their journalists, plus a small number of activist organizations and especially high-profile activists. What we do not see, however are any obvious traces of the alleged grassroots mobilization going on. Neither are any government actors from any country present in the network core.

One way of exploring the remaining 86 percent of network flow further is to apply the bowtie theory of the web to the graph presented in Figure 1 (Barabási 2002, 166; Broder et al. 2000). According to this theory, directed networks - such as links between websites, or the Twitter network under analysis in this paper - break down naturally into a set of well-defined 
parts, or "continents". In the central core, each node is linked to any other node in the sense that each node can be reached from any other node. Mimicking the rough image of a bowtie, the central core is flanked by an "in-continent" on the one hand and an "out-continent" on the other. Nodes in the in-continent are arranged so that following their links will eventually lead you to the core of the network. All nodes in the out-continent can be reached by following links from the core, but once they have been reached, no links are going back to the center. These concepts are of use to answer where the action really is in the Twitter discourse under study. If we look only at network flow, we will end up with a description of the \#feb17 discourse as ruled mainly by news corporations and a small number of activists and activist organizations, most of these coming from locations far away from where the revolution is taking place. But what happens if we put the direction of communication under closer analysis?

Using Gephi to disentangle Figure 1 a more schematic visualization of the same discursive space could be achieved. By looking at the network metrics of in-degree and outdegree, instead of just degree (which obscures directionality), and by looking up the Twitter profiles of key accounts in the respective continents, the patterns illustrated in Figure 2 were found. Accounts were sorted into the continents based on the relationship between their inand out-degrees. The in-degree of each node was divided by the total degree of that same node to achieve a measure of how much of the traffic at each specific Twitter account derived from incoming tweets. Accounts with a value of 0.75 or more were seen as belonging to the out-continent, since these are accounts that mainly receive messages. Accounts with a value of 0.25 or less were sorted into the in-continent, since they are mainly sending messages. All other accounts $(0.26-0.74)$ were defined as belonging to the central core since they have a balance between sending and receiving messages.

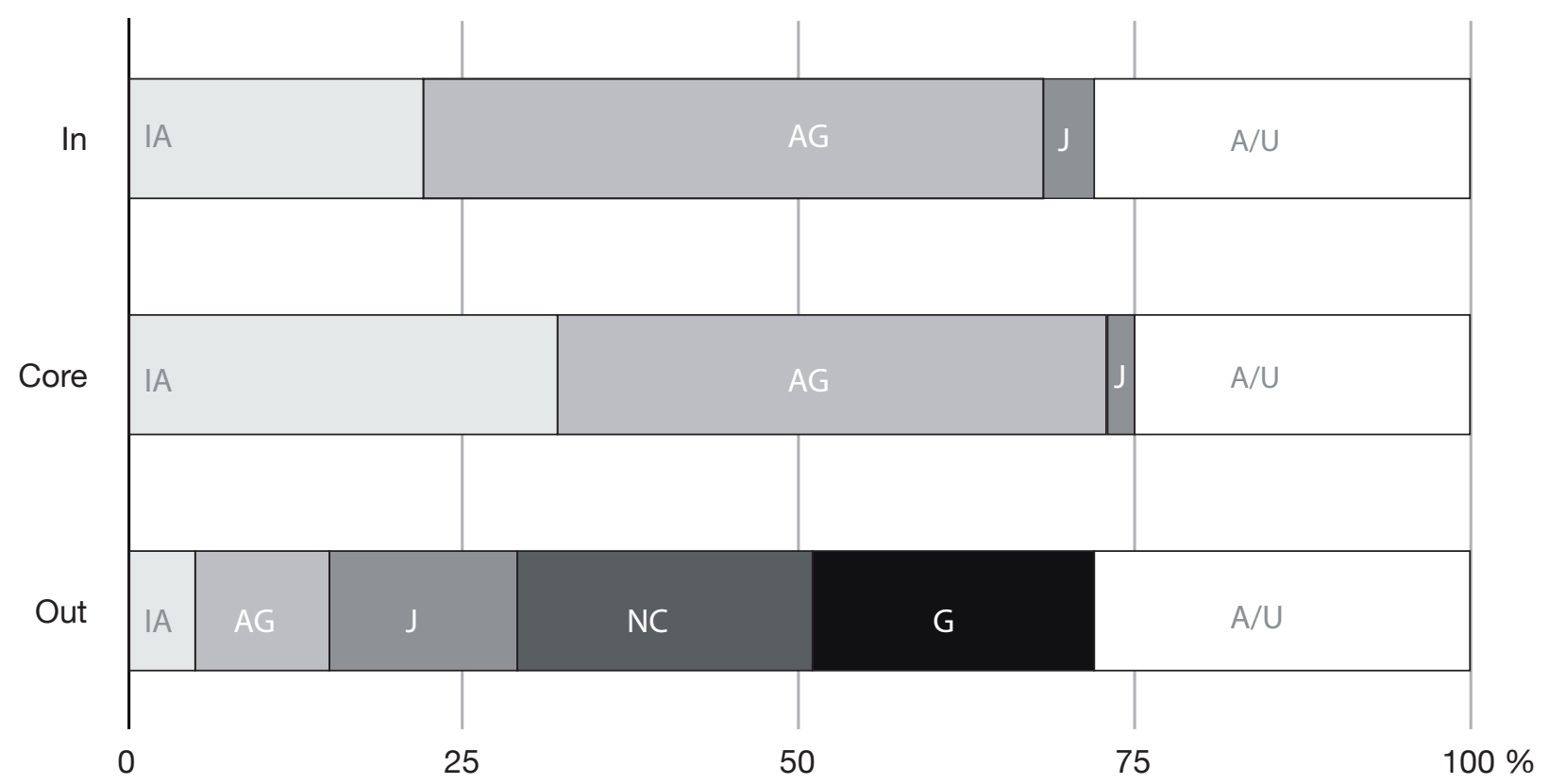

Individual activists (IA)

Activist groups (AG)
Journalists $(\mathrm{J})$

News corporations (NC)
Governments (G)

Anonymous/unidentified (A/U)

Figure 2: User groups divided into the continents of the directed network

As Figure 2 shows, a categorization of Twitter accounts in terms of user type was made. The first category was labeled Individual activists (IA), and includes Twitter accounts belonging to individuals rather than organizations and that used the \#feb17 hashtag to communicate messages about events relating to the Libyan uprising. Accounts affiliated with political NGOs 
were categorized as belonging to Activist groups (AG), and accounts where profiles clearly stated that their owners are journalists were consequently categorized as "Journalists" (J). Official accounts of news corporations were sorted as such (NC) and governmental accounts - these were exclusively European or North American - were also collected in their own category $(G)$. As this categorization was made through a combination of manual and automated searches in lists of scraped profile data, and since most accounts on Twitter are not verified, the categorization is not exact. In fact, a relatively large portion of the accounts had to be coded as "Unidentified/anonymous". Still, from a qualitative standpoint, it can be claimed that the categorization aids in discerning some important differences between user types as regards which network continent they belong to.

Firstly, governments and news organizations are to be found in the out continent. This means that they are tweeted to and about. They are mentioned as topics for discussion, and receive criticisms or calls for attention or help. To a much lesser extent, if ever, are they taking an active part in the exchanges that contribute to keeping the center core of the network together. A similar pattern goes for the journalist accounts, even though some journalists are also active as parts of the in continent and core. Secondly, activists and activist groups dominate the in continent as well as the central core. They are feeding information into the network by mentioning and replying to other participants. These actors appear to be engaged in relationships based on giving and/or mutuality. While it might not be unexpected that journalists and activists have different usage patterns, it might be an insight that the latter engage in ways that more fully take advantage of the networked architecture of the Twitter platform.

The main conclusion to be drawn from Figure 2 is that while some traditional actors appear at the center of a map based solely on degree, the actual agents and interactors of the network come into view if we take the direction of communication into consideration. In the particular case of the \#feb17 hashtag, a mapping based simply on how much network flow passes through a given node, regardless of direction, leaves the impression that the discourse is dominated by media corporations and a small number of NGOs and particularly prominent individual activists - largely from the world outside of Libya. If, however, the network metrics of in- and out-degree are used to bring the directionality of the communicative relationships into view, a different landscape unravels, where the share of North African accounts and tweets in Arabic seems to be significantly larger. Furthermore, accounts that had peripheral positions in Figure 1 then appear as key agents, and accounts that were at the center of that same graph are revealed to be quite passive. The operation is elementary, next to trivial, from the perspective of network analysis. Still the differences in possible interpretations of Figure 1 as compared with Figure 2 are quite striking. The first way of visualizing the network would suggest that grassroots mobilization is a minority phenomenon in in the analyzed dataset, while the second approach supports a view of individual activists and activist organizations as the prime movers of the studied Twitter discourse.

\section{Three Discourses}

In Internet activism, network structures are interwoven with their linguistic content (Hands $2011,91)$. Therefore, it is important to look not only at who says something, and to whom, but also at what is actually said. In order to explore this dimension the content of tweets in the dataset were analyzed through connected concept analysis (Lindgren 2012) using Textometrica (Lindgren and Palm 2011). Word frequency lists, complemented by manual searches and qualitative conceptual coding (Lindgren 2012) were used to establish a set of concepts to map. The result was visualized using Gephi. As Figure 3 shows, "Al Jazeera" is the most commonly used concept in the material. It links to conceptual groups referring to "US Media", "UK Media" and "Al Arabiya" in a discursive context revolving around key concepts like "corruption", "lies, "truth", "silenced", "oppression", "propaganda" and "false information". This mid-left section of the graph illustrates the presence of a prominent theme revolving around the struggle for objective reporting and for turning the eyes of the outside world to the events in Libya. Tweets like the following are examples of this discourse category, labeled in Figure 3 as "Calling out": 
@AJEnglish Protesters chanting, "Oh Media! Where are you? Where are you?" can barely hold back the tears as I write... \#Feb17

@AJEnglish covering Libya right now, THANK YOU! \#Feb17 \#Libya \#Benghazi

@LibyaDemocracy: \#FEB17 ALL CAMERAS BANNED IN \#LIBYA ! MEDIA WE NEED YOU!PEOPLE ARE BEING SLAUGHTERED!

@BBCWorld http://bbc.in/gyZFLF is currently reporting about \#libya .. please keep it up! \#feb17

@AJArabic @AJEnglish @jrug \#Libya \#Feb17 PLS SHOW THIS URGENT

URGENT!! @BBCWorld @cnnbrk @ajtalk @UN NEED THE WORLD TO SEE THE CRIMES

GADDAFI IS COMMITTING TODAY! \#libya \#feb17

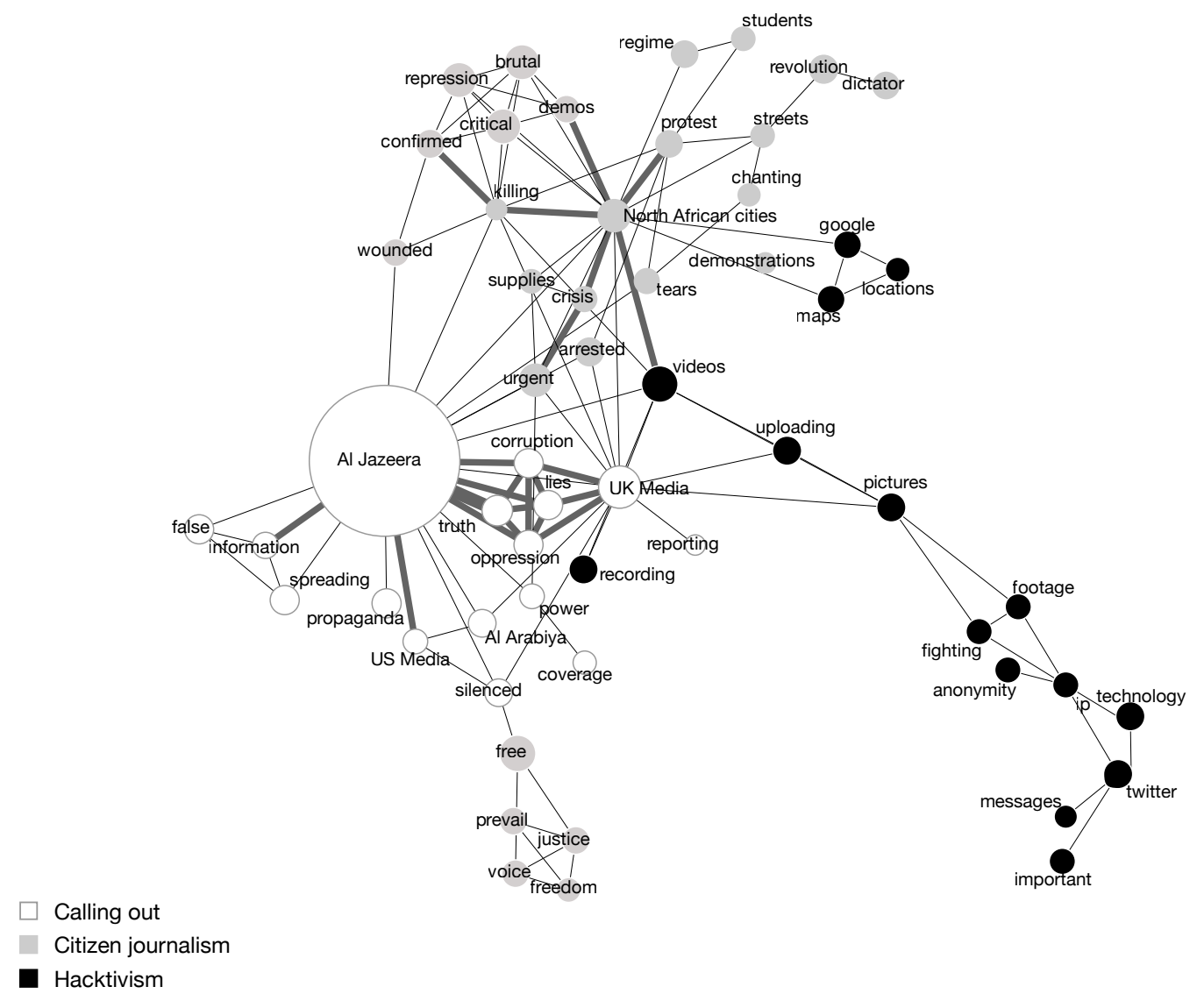

Figure 3: Discursive themes employed in the \#feb17 hashtag

The top-mid section of the graph depicts another prominent theme in the \#feb17 discourse. This is an aggregation of concepts relating to street level reports. Names of cities are mentioned in conjunction with words and formulations relating to "demonstrations", "streets", "students", "chanting", "wounded", "arrested", "tears", "supplies" etc. These tweets are typically about giving a live account of what is happening in demonstrations and to coordinate activities as they happen. The following tweets are examples of this: 
@ShababLibya: \#Benghazi your city is calling you, Take to the streets. head for Maydan al Shajara \#Feb17 \#Libya

@ShababLibya: contact in benghazi: the city is upside down, all shops closed \#Sidibouzid \#Jan25 \#Feb17 \#Libya

$@[\ldots]$ : Downtown \#Benghazi NOW! Protesters being shot at in front of the Nasr soccer club! \#Libya \#Feb17

@Number10gov URGENT! Shortage of medical supplies in Al Bayda hospital, calling on ALL int'I health organizations to help \#Libya \#Feb17

$@[. .$.$] : \#libya is revolting. we're organizing a protest at the downtown library, 1 \mathrm{pm}$ on saturday. come out. \#feb17 \#gaddafi is goin down

Finally, the mid-to-bottom right section illustrates a group of concepts relating to hacktivist activities. The term hacktivism refers to "the fusion of hacking and activism; politics and technology" (metac0m 2003). It is about situations and strategies where digital tools are used with the purpose of campaigning and working for social and cultural change (Jordan 2002; Jordan and Taylor 2004). This conceptual sub-network is connected both to the street level theme and the "calling out" theme, and revolves around the promotion, and actual practice, of using digital media to document and broadcast the rebellion. The importance of taking "pictures" and "videos" and of "uploading" them to social media platforms is underlined in these tweets:

@EnoughGaddafi: visit this site http://www.libyafeb17.com to post videos and documents related to the uprising \#Feb17 \#Libya

@[...]: use http://bambuser.com/ Live video streaming from your mobile phone or webcam

@[...]: try to include a hash-tag with your post, for example \#Libya or \#Feb17

@ShababLibya: Eyewitness on the ground: a local of \#Benghazi just been killed! SPREAD THE WORD PPL WE NEED YOUR HELP \#Libya \#Feb17

@[...]: PLEASE ERASE ANY AND ALL INFO FROM YOUR PHONES (INCLUDING PICS \& VIDEOS) AS THEY WILL BE CHECKED AT CHECKPOINTS \#FEB17 \#BAHRAIN

@[...]: Do NOT erase Video's and Photo's. Save them to memory card and hide memory card on your person \#feb17 \#Bahrain

@enoughgaddafi website hacked. Everyone change up your passwords they're bringing it hard. \#libya \#feb17 \#Benghazi

In sum, three main themes make up the discursive field of \#feb17: "Calling out", "Street level reports" and "Hacktivism". Looking at the centrality of these respective themes, "Calling out" stands for 29 percent of the network flow while "Street level reports" and "Hacktivism" correspond to 37 and 32 percent respectively. This means that the amount of discussion devoted to these subjects is close to equally distributed.

\section{Between Emancipation and Repression}

This article set out to use the case of the Libyan uprising of 17 February 2011 to discuss the potentials and limitations of social media as a tool for activists. The purpose was to contribute to knowledge about what actually happens when social media is put to use in relation to concrete events. This venture should be seen in the light of the ongoing debate of the actual role of new digital media platforms and tools in the politics of resistance throughout today's world. As summed up at the outset, some commentators are sceptical about what social media have to contribute, sometimes claiming that they may have oppressive rather than libera- 
tory effects. Others are more optimistic and view social media as key driving forces for several current uprisings.

Looking for activism under the \#feb17 hashtag, I found two key clusters of users included in the Twitter discourse relating to these events in Libya. The activist cluster and the news corporation clusters were of similar strength, and represented just 14 percent of all network flow. Focusing then on the directionality of the network, now including all users, we found that activists indeed seem to function as driving forces, while governments and news corporations achieve their prominent role in the communication network mainly by receiving calls for attention from activists, citizen journalists and other individuals or groups. The analysis of the content of tweets also showed that the things that are tweeted about are not random, but follow a certain discursive structure based on themes that are relevant for activist and movement practice. This leads us to the conclusion that social media, like Twitter, may potentially function as alternative media platforms where a voice other than that of corporate media or prevailing regimes dominates. These social network patterns, as well as the content of the posts, resonate with what Enzensberger (1970) calls "emancipatory use of media": The architecture is decentralized, network connections are distributed, and mobilization and self-organization is going on.

It must be realized however, that seeds of such emancipatory use does not necessarily preclude "repressive use of media" (ibid.). Even if a certain topic (e.g. the \#feb17 communication) on Twitter is dominated, or even controlled, by activists rather than corporations or governments, this dominance or control relates just to certain slices of content on the platform as a whole. Even though underground, and much less widely used, alternatives exist (Lovink and Rasch 2013), platforms like Facebook and Twitter are in themselves owned by large corporations that at anytime may monitor users, censor content, or take the platforms down altogether (CBSNews 2012). As Fuchs $(2011,277-8)$ shows: "[...] there is a stratified online attention economy in which the trademarks of powerful media actors work as powerful symbols that help the online portals of these organizations to accumulate attention [...] (And) corporations that are profit oriented and accumulate capital by online advertising and in some cases by selling special services operate the vast majority of web 2.0 platforms."

We must also remember, that the results presented in this article are derived solely from an analysis of the textual level. But only because activist tweeting occurs, this does not automatically mean that the tweets contribute to actual social change. One might still be dealing with "slacktivism" (Christensen 2011; Morozov 2009), "clicktivism" (White 2010) or what Dean $(2009,11)$ calls "post-politics". Politics is indeed a minority issue on Twitter, and that Twitter - in spite of it being lauded as a tool for democratization - is in fact not a broadly used political platform (Larsson and Moe 2012).

There are of course no social media revolutions. Conceptualizations like "Facebook revolution" or "Twitter revolution" are inherently techno-deterministic. They are based on the assumption that the introduction or implementation of a certain technological 'solution' will bring about certain effects that stretch far beyond the technological into the social, economic and historical. Actual revolutions are always historically embedded and spring from frictions at the level of people's everyday lives. When revolutions come about, they tend to be seen as "the inevitable outcome of powerful social forces" (Kuran 1989, 42), and the question is how powerful a force social media as such can constitute. In 1919, North Africa saw simultaneous uprisings in Tunisia, Egypt and Libya in the aftermath of World War I. Those events illustrate that Facebook or Twitter, or the Internet, is not needed for the global diffusion of information and expectations. In fact, the 1919 uprisings were inspired by Woodrow Wilson's Fourteen Points speech which made its way across the globe by telegraph (Anderson 2011).

While Libyan activists obviously used social media to share ideas and develop tactics, historically rooted cleavages and agencies are needed for technologies and aspirations to resonate into becoming a true revolution. Why revolutions come about is a wide-stretching field of inquiry for historians, sociologists, economists and political scientists. Social media revolutions, however, do not come about. Social media are tools for co-ordinating networked publics, and they are fairly new. This means that the present day study of revolutions and upris- 
ings certainly needs expertise from the field of Internet research, but the question will never be whether social media made the revolutions happen in the first place.

\section{References}

Adorno, Theodor W. and Max Horkheimer. 1947. Dialectic of Enlightenment. London: Verso.

Anderson, Chris. 2006. The Long Tail: How Endless Choice is Creating Unlimited Demand. London: Random House Business.

Anderson, Lisa 2011. Demystifying the Arab Spring. Foreign Affairs 90 (3), 2-7.

Anstead, Nick and Andrew Chadwick. 2008. Parties, Election Campaigning, and the Internet. Toward a Comparative Institutional Approach. The Routledge Handbook of Internet Politics, 56-71.

Bailey, Olga G., Bart Cammaerts and Nico Carpentier. 2008. Understanding Alternative Media. Maidenhead: McGraw Hill/Open University Press.

Barabási, Albert-Lázló. 2002. Linked: The New Science of Networks. Cambridge, Mass.: Perseus Books.

Bastian, Mathieu, Sebastien Heymann and Mathieu Jacomy. 2009. Gephi: An Open Source Software for Exploring and Manipulating Networks. Paper presented at the AAAl Conference on Weblogs and Social Media, San Jose, California.

Boehlert, Eric. 2009. Bloggers on the Bus: How the Internet Changed Politics and the Press. New York: Free Press.

Bourdieu, Pierre. 1977. The Economics of Linguistic Exchanges. Social Science Information 16, 645668.

Broder, Andrei, Ravi Kumar, Farzin Maghoul, Prabhakar Raghavan, Sridhar Rajagopalan, Raymie Stata, Andrew Tomkins and Janet Wiener. 2000. Graph Structure in the Web. Computer Networks 33 (1), 309-320.

Bruns, Axel, and Jean Burgess. 2011. The Use of Twitter Hashtags in the Formation of Ad Hoc Publics. Paper presented at the European Consortium for Political Research Conference, Reykjavik (25-27 August), at http://snurb.info/node/1533, accessed 23 March 2013.

Burns, Alex and Ben Eltham. 2009. Twitter Free Iran: An Evaluation of Twitter's Role in Public Diplomacy and Information Operations in Iran's 2009 Election Crisis. In: Communications Policy \& Research Forum 2009, 19th-20th November 2009, University of Technology, Sydney.

CBSNews. 2012. Twitter's Censorship Plan Rouses Global Furor. CBSNews. http://www.cbsnews.com/8301-205_162-57367843/twitters-censorship-plan-rouses-global-furor/

Chadwick, Andrew and Philip N. Howard. 2008. Routledge Handbook of Internet Politics. London: Routledge.

Christensen, Henrik Serup. 2011. Political Activities on the Internet: Slacktivism or Political Participation by Other Means? First Monday 16 (2).

Cottle, Simon. 2011. Media and the Arab Uprisings of 2011: Research Notes. Journalism 12 (5), 647659.

Dean, Jodi. 2009. Democracy and Other Neoliberal Fantasies: Communicative Capitalism \& Left Politics. Durham, [N.C.]: Duke University Press.

De Nooy, Wouter, Andrej Mrvar and Vladimit Batagelj. 2011. Exploratory Social Network Analysis with Pajek. New York: Cambridge Univ Pr.

Deleuze, Gilles and Felix Guattari. 1987. A Thousand Plateaus: Capitalism and Schizophrenia. Minneapolis: University of Minnesota Press.

Downey, John, and Natalie Fenton. 2003. New Media, Counter Publicity and the Public Sphere. New Media \& Society 5, 185-202.

Enzensberger, Hans Magnus. 1970. Constituents of a Theory of the Media. New Left Review 1, 64.

Fraser, Nancy. 1990. Rethinking the Public Sphere: A Contribution to the Critique of Actually Existing Democracy. Social Text (25/26), 56-80.

Fuchs, Christian. 2011. Foundations of Critical Media and Information Studies. London: Routledge.

Galloway, Alexander R. 2004. Protocol: How Control Exists after Decentralization. Cambridge, Mass.: MIT Press.

Gessen, Keith. 2012. Occupy!: Scenes from Occupied America. London: Verso.

Gibson, Rachel, Andrea Römmele and Stephen Ward. 2003. German Parties and Internet Campaigning in the 2002 Federal Election. German Politics 12 (1), 79-108.

Grossman, Lev. 2009. Iran Protests: Twitter, the Medium of the Movement. Time Magazine 17. 
Hands, Joss. 2011. @ Is for Activism: Dissent, Resistance and Rebellion in a Digital Culture. London: Pluto.

Harfoush, Rahaf. 2009. Yes We Did: An Inside Look at How Social Media Built the Obama Brand. San Fransisco: Pearson/New Riders.

Hooghe, Marc and Wouter Teepe. 2007. Party Profiles on the Web: An Analysis of the Logfiles of Non-Partisan Interactive Political Internet Sites in the 2003 and 2004 Election Campaigns in Belgium. New Media \& Society 9 (6), 965.

Jansen, Fieke. 2010. Digital Activism in the Middle East: Mapping Issue Networks in Egypt, Iran, Syria and Tunisia. Knowledge Management for Development Journal 6 (1), 37-52.

Jenkins, Henry. 2006. Convergence Culture: Where Old and New Media Collide. New York: New York University Press.

Joffé, George. 2011. The Arab Spring in North Africa: Origins and Prospects. The Journal of North African Studies 16 (4), 507-532.

Jordan, Tim. 2002. Activism! Direct Action, Hacktivism and the Future of Society. London: Reaktion Books.

Jordan, Tim and Paul A. Taylor. 2004. Hacktivism and Cyberwars: Rebels with a Cause? New York, N.Y.: Routledge.

Kahn, Richard and Douglas Kellner. 2003. Internet Subcultures and Oppositional Politics. In The PostSubcultures Reader, edited by David Muggleton and Rupert Weinzierl, New York: Berg.

Keen, Andrew. 2007. The Cult of the Amateur: How Blogs, MySpace, YouTube, and the Rest of Today's User-Generated Media Are Destroying Our Economy, Our Culture, and Our Values. New York: Doubleday.

Khondker, Habibul Haque. 2011. Role of the New Media in the Arab Spring. Globalizations 8 (5), 675679.

Kuran, Timur. 1989. Sparks and Prairie Fires: A Theory of Unanticipated Political Revolution. Public Choice 61 (1), 41-74.

Larsson, Anders Olof and Hallvard Moe. 2012. Studying Political Microblogging: Twitter Users in the 2010 Swedish Election Campaign. New Media \& Society 14 (5), 729-747.

Lindgren, Simon. 2012. Introducing Connected Concept Analysis: Analyzing Social Media Flows Through a Qualitative Approach to Quantity. Forthcoming.

Lindgren, Simon and Fredrik Palm. 2011. Textometrica: Service Package for Text Analysis. Umeå: HUMlab.

Lovink, Geert and Miriam Rasch, eds. 2013. Unlike Us Reader: Social media Monopolies and Their Alternatives. Amsterdam: Institute of Network Cultures.

Mason, Matt. 2008. The Pirate's Dilemma: How Youth Culture Is Reinventing Capitalism. New York: Free Press.

Mason, Paul. 2012. Why It's Kicking Off Everywhere: The New Global Revolutions. London: Verso. metac0m. 2003. What is Hacktivism? 2.0. http://www.thehacktivist.com/whatishacktivism.pdf.

Morozov, Evgeny. 2009. The Brave New World of Slacktivism. Foreign Policy 19.

Morozov, Evgeny. 2011. The Net Delusion: The Dark Side of Internet Freedom. New York: Public Affairs.

Munteanu, Igor and Alina Mungiu-Pippidi. 2009. Moldova's "Twitter Revolution". Journal of Democracy 20 (3), 136-142.

Poster, Mark. 2009. Global Media and Culture. New Literary History 39, 685-703.

Rheingold, Howard. 2002. Smart Mobs: The Next Social Revolution. Cambridge, Mass.: Perseus.

Shirky, Clay. 2009. Here Comes Everybody: How Change Happens When People Come Together. London: Penguin.

Skinner, Julia. 2011. Social Media and Revolution: The Arab Spring and the Occupy Movement as Seen through Three Information Studies Paradigms. Sprouts: Working Papers on Information Systems 11(169).

Smith, Catharine. 2011. Egypt's Facebook Revolution: Wael Ghonim Thanks the Social Network. The Huffington Post.

Tolbert, Caroline J. and Ramona S. Mcneal. 2003. Unravelling the Effects of the Internet on Political Participation? Political Research Quarterly 56, 175-185.

Varnelis, Kazys. (Ed.). 2008. Networked Publics. Cambridge, Mass.: MIT Press.

Vergeer, Maurice, Liesbeth Hermans and Steven Sams. 2011. Is the Voter Only a Tweet Away? Micro blogging during the 2009 European Parliament Election Campaign in the Netherlands. First Monday $16(8-1)$. 
Wasserman, Stanley and Katherine Faust. 1994. Social Network Analysis: Methods and Applications. Cambridge: Cambridge University Press.

White, Micah. 2010. Clicktivism Is Ruining Leftist Activism. The Guardian.

\section{About the Author}

\section{Simon Lindgren}

is Professor of Sociology at Umeå University, Sweden. He researches digital culture with a focus on how new media audiences navigate the border landscape between the new potentials for participation and activism on the one hand, and the risks for exclusion and exploitation on the other. Simon is actively taking part in developing theoretical as well as methodological tools for analyzing discursive and social network aspects of the emerging new media landscape. He has published internationally on themes like hacktivism, digital piracy, citizen journalism, subcultural creativity, popular culture and visual politics. More information can be found at www.simonlindgren.com. 